\title{
The Grammar of English Proper Names
}

\author{
RALPH B. LONG
}

\section{$\mathrm{I}_{\mathrm{s}}$}

N A PAPER entitled "The Linguistic Component of Onomastics" (Names, 1963) Professor Utley says that "a grammar which does not include proper names is no grammar at all." Certainly proper names follow distinctive patterns of syntactic behavior and should be among the concerns of even very brief grammars. I suppose that the most naive of school grammars gives some attention to proper names. The school-grammar definition of the term "noun" - "the name of a person, place, or thing" - in itself insures attention not only to such words as girl and city but also to such words as Mary and Boston. Yet the most influential treatments of English grammar to appear in the States in the fifties and sixties do very little, sometimes nothing at all, with proper names. At the end of the forties Professor McMillan wrote, in a paper entitled "Observations on American Place-Name Grammar" (American Speech, 1949), that specialized students of names are better qualified to contribute the facts of proper-name grammar than are "general grammarians." As a general grammarian, I find myself in full agreement on this point. When I write about proper names, I do so on the basis of what I myself consider an inadequate supply of facts. Still, I am convinced that the grammarian's approach to matters such as this is a valid one and should be given expression. In this paper I will attempt to formulate, tentatively, a defensible minimal account of the grammar of proper names in contemporary English, and will then comment briefly on what has been done with this topic in the most influential accounts of English grammar from Professors Trager and Smith's An Outline of English Structure (1951) to Professor Lamb's Outline of Stratificational Grammar (1966). In my account of the grammar of proper names, I will distinguish between what I regard as true proper nouns, which characteristically are single words, and phrasal proper names. In dealing with proper names, I will concern myself with written-language words and combinations 
of words, not with morphemes. The morphemic analysis of proper names inevitably involves complex questions both of historical fact and of present-day perception. Such proper nouns as Charleston, Newton, Milton (apparently parallel in historical composition to both Middletown and Milltown), and Washington show something of the problems morphemic analysis faces. The word is a troublesome unit at some points: thus in timetables American Airlines writes airlines as a single word and United Air Lines writes the same combination as two words. In his Introductory Linguistics (1964) Professor Hall maintains that the word "is not to be taken seriously as a useful concept in linguistic analysis." But in spite of their occasional troublesomeness, words - written words are accepted institutional units, and it is interesting to note that Professor Hall defines the noun as "any word that you can put the in front of" - a definition, incidentally, which makes it hard to include most proper nouns. Any word, Professor Hall says, not any morpheme or combination of morphemes.

From the point of view of grammatical behavior, nouns are of three kinds: pluralizers such as the visitor of visitors help people forget their troubles, quantifiables (modifiable by much and not made plural) such as the company of company helps people forget their troubles, and proper nouns such as the Virginia of Virginia helps people forget their troubles. Nouns are characteristically usable as one-word subjects, as visitor (in its plural form, not in its singular form), company, and Virginia are used in the sentences just given. Pronouns are usable as one-word subjects too: I am ignoring them at this point. Some words whose syntactic functioning is exceptionally restricted must be classified as nouns even though they are not used as one-word subjects in standard contemporary American English: the honorifics $M r$., Mrs., and Miss, for examples, are pluralizer nouns; and Bronx and Antilles are proper nouns. Some words are nouns of one kind in some uses and nouns of another kind in other uses. Thus company is a quantifiable noun when its meaning is close to that of visitor, as in we haven't had much company this week, but a pluralizer when its meaning is close to that of corporation, as in it's hard to compete with the big companies; and 
mother is a pluralizer noun in $I$ told my mother but a proper noun in $I$ told Mother. Some proper nouns are identical in internal form and in origin with words of quite different part-of-speech classifications, and their meanings in these other uses are not always forgotten in their proper-name uses. This is most noticeable, perhaps, in the names of race horses, which can apparently be drawn from any section of the general vocabulary. Used as names of horses, such words as More, Sincere, Unintentionally, and Communicate must be described as proper nouns.

At what I suppose Stratificationalists would call the semantic or sememic stratum in linguistic analysis, the basic distinction between proper nouns on the one hand, and pluralizers and quantifiables on the other, is the fact that proper nouns are characteristically individual in application. Thus Virginia is a word used as a name for individual people, pets, dolls, places, musical and literary compositions, perhaps even hurricanes: the applications given to the word are innumerable, and yet in each of its proper-name applications the central meaning it conveys is individual. When we say Virginia helps people forget their troubles, by Virginia we mean some particular person. The effective central meanings of proper nouns in true proper-name uses are unique meanings. The honorific capital letters with which most proper nouns are begun are a tribute the written language pays to individuality and have no equivalent in the spoken language, in which Virginia dislikes Brown, with the object of Virginia's dislike a person, is not distinguishable in internal form from Virginia dislikes brown, with the object of her dislike a color.

At what I suppose Stratificationalists would describe as the lexemic stratum of analysis - I myself prefer the old-fashioned term "syntactic" to "lexemic" - proper nouns are distinguished from pluralizers and quantifiables ( 1 ) by their usual rejection of modifiers of types pluralizers and quantifiables accept freely and (2) by the fact that they are not freely usable both in the singular and in the plural, as most pluralizers are, or with quantification of the type involved in modification by much, as quantifiables are.

Two types of modifiers are notably incompatible with propernoun heads: determinative modifiers such as the, this and these, that and those, some, and possessives; and tight (identifying) relative clauses in which unstressed that functions as elause marker. Thus the visitors have left and the company has left are satisfactory sentences 
but the Virginia has left usually is not, and no one wants visitors that stay too long and no one wants company that stays too long are satisfactory sentences but no one wants Virginia that stays too long usually is not. Actually proper nouns do not take very many kinds of tight modifiers freely. Those applied to people take honorifies, mostly nouns, such as the Aunt of Aunt Virginia, the Professor of Professor Carter, and the $M r$. of $M r$. Brown. Descriptive (often emotional) adjectives and adjectival phrases such as the poor of poor Virginia, the pompous of pompous $M r$. Brown, and the twelve-year-old of twelve-year-old Nancy are certainly not uncommon, nor are divisional modifiers such as the southern of southern Ohio. Adverbs such as even and only often modify proper nouns, as in even Virginia and only Mr. Brown.

When determinative modifiers of identification are used with nouns that would be characteristically individual in application without them, the use is both redundant and antisystematic; nevertheless the definite article the is used with a considerable number of such nouns. Singular proper nouns used with the include exceptional literary titles such as Koran, exceptional names of political units such as Bronx, names of rivers such as Ohio, and names of ships such as Bremen. Plural proper nouns are characteristically used with the, including such names of island chains as Antilles, such names of mountain ranges as Adirondacks, and such names of complex systems of lakes or swamps as Everglades. Such words as renaissance and reformation become proper nouns, normally in combination with the, when they are used as fixed designations of particular historical events or movements, as in Shakespeare was a product of the Renaissance. In nounal constructions, the article used with proper nouns such as these is compulsory and invariable. We can speak freely of the borough, that borough, every borough, no borough, and your borough but (with equal freedom) only of the Bronx. We can speak freely of the islands, those islands, all islands, no islands, and Holland's islands but (with equal freedom) only of the Antilles. Actually, combinations of compulsory the and proper nouns constitute simple phrasal proper names. And though they are syntactically antisystematic, they do often serve to eliminate ambiguity. Thus we can usually be reasonably sure that Ohio is a state and the Ohio a river, and that Bremen is a city and the Bremen a ship. 
In addition to the the that is normally compulsory with nouns such as Bronx and Antilles, we face the fact of occasional uses of determinative modifiers and tight modifying that clauses with what would otherwise be classified as proper nouns without question. When we say I didn't mean that Virginia, I meant the Virginia that lives on Jackson Street, certainly Virginia no longer has either the meaning or the syntax of proper nouns. In this sentence Virginia simply means person named Virginia, and is a pluralizer. In the new $C u b a$ we are on a borderline. It is possible to conceive of a series of distinct Cubas comparable to a sequence of human beings made up of great-grandfather, grandfather, father, and son: an eighteenthcentury Cuba, a nineteenth-century Cuba, etc. If we take this view of the matter, we can justifiably say that $C u b a$ is a pluralizer in the new $C u b a$ and the use of the article the is entirely normal. But we are on a borderline. In the following sentences from Sinclair Lewis' Arrowsmith it is hard to think of Leora as anything but a proper noun modified, exceptionally, by determinatives that are certainly not compulsory.

Then Martin also went rapidly away, accompanied by a furious Leora.

It was the detached and fearless Leora who was mature.

This seems to be the best view to take of such phrases as the late Sterling A. Leonard and that old Truman Capote, where phrasal proper names rather than one-word proper nouns function as heads, and of such phrases as the Emperor Maximitian.

At the semantic or sememic stratum of analysis, perhaps all proper names should be singulars, since what they name is strongly felt as individual. Or better, like quantifiable nouns such as company (meaning "visitors"), postage, anger, and milk they should be regarded as not involved in considerations of number at all, since they lack even the fundamental contrast between singular and plural. But at the syntactic stratum certainly we must recognize that most proper nouns take singular verbs but some take plural, and that pronouns referring to most proper nouns are usually singular but pronouns referring to some are usually plural. Thus Popocatepetl and Martinique are singular proper nouns in syntax but Andes and Windwards are plural proper nouns. Simple nonplural forms of some plural proper nouns are used as modifiers of other nouns, as Adirondack is used in the Adirondack Mountains; other- 
wise proper nouns characteristically stay on one side of the line between singular and plural. For this reason instead of St. Croix is a Virgin it is usual to say St. Croix is one of the Virgins. We can of course say there are three Virginias in the class and there are too many Washingtons in the United States, but when we do we have made pluralizers out of Virginia (which now means simply girl named Virginia) and Washington (which now apparently means places named Washington). The effective central meanings of proper names are much more individual than such meanings as these.

The syntactically important characteristics of proper nouns are (1) their usual rejection of determinative modifiers and tight relative clauses in which that functions as clause marker and (2) their lack both of singular-plural contrast and of quantification of the kind expressed by such words as much. They are grammatically distinctive, though not decisively so, in other ways too. Thus whereas many nouns of other types are not likely to be made possessive and quantifiables such as postage are not likely to be inflected at all - most proper nouns occur in possessive forms and functions with relative freedom, so that it is quite natural to speak of Virginia's teachers or of Haiti's relations with the Dominican Republic. Proper nouns applied to people are used in the essentially adverbial function of adjuncts of direct address - as in that's yours, Virginia much more often than other nouns are. Virginia! can serve as a call or as an expression of emotion of some kind, whether pleasure, irritation, or simple surprise: in such uses proper names function as nonclausal sentences. Finally, though at most points sex is of less importance than it was in older English - so that, for example, governor corresponds to both duke and duchess - sex is usually taken into account when given names are assigned to people, animals, or dolls.

In general, the written language begins proper nouns with honorific capital letters. But initial capitals are also assigned to many nouns that are not proper nouns, and even to adjectives and verbs based on proper nouns such as the adjective American and the verb Americanize. Names of languages are begun with capital letters and yet are quantifiables rather than true proper nouns, as such sentences as Judy doesn't know much Spanish make clear. Nouns like Spaniard and Virginian are pluralizers, not proper nouns, as such sentences as a Spaniard and two or three Virginians were looking 
out at the laurel make plain. Though the purpose of trade names is to make products seem individual and thus quite unlike competing products, and though genuinely imaginative trade names do achieve this purpose sometimes, trade names are pluralizers and quantifiables, not proper nouns, as such sentences as do you have a Kleenex? and you're taking too much Equanil demonstrate. Though it is a proper noun in Friday is the last day of classes, the noun Friday is a pluralizer in you've missed class the last three Fridays.

Some nouns that are not begun with capital letters require classification as proper nouns, at least in some of their uses. Thus in heaven and hell are one place, and we all go there both heaven and hell are true proper nouns in behavior. Though the old prepositional phrase afternoon is usually a pluralizer noun, the similarly formed word today is usually a true proper noun in grammar. Thus we say today is a bank holiday but this afternoon is a poor time to call on people. Such nouns as town confront us with a problem when we look at sentences like we get to town at least once a week and all through the Appalachians, country people generally get to town at least once a week now. In the first of these two sentences town can be as specific in effective meaning as Asheville would be. In the second, town is general in meaning. The simple form town can be used in these ways in some nounal constructions but not in others. In the subject construction the undetermined simple form would not be used either when the sense was individual or when it was general. Thus we would say the town (hardly just town) is ten miles away and towns are (not town is) scattered through the mountains. Town forces us to decide where we want to place a doubtful borderline. I myself would prefer to call town a pluralizer in all the uses I have noted, but a pluralizer that is used in exceptional ways. The noun sun confronts us with still another problem. Used with the meaning of sunshine, as in be careful not to get too much sun the first few days, the word sun is a quantifiable noun. Applied to the celestial body around which the earth revolves, the noun sun is certainly a pluralizer in modern scientific use. Even in popular use, where it would seem that the sun would deserve a proper name as much as Sirius and Mars do, and that the sun might be a phrasal proper name like the Bronx, the noun sun seems to be more like the pluralizers star and planet than like the proper nouns Sirius and Mars in its behavior, in that it accepts that clauses as tight modifiers, as well as the - as in the sun that shines above us. 


\section{II}

Like one-word proper nouns, phrasal proper names are individual in application and in the written language are generally assigned honorific capital letters in recognition of this individuality. Like one-word proper nouns, they are not compatible with modification by varied determinatives or by tight relative clauses in which unstressed that functions as clause marker. Like one-word proper nouns, they do not easily cross the line that separates singulars from plurals nor do they accept quantification of the type involved in modification by much.

Some phrasal proper names contrast with parallel nonproper phrases because of their lack of determinative modifiers where the nonproper phrases have them. Long Island is distinguished in this way from a long island, the long island, that long island, etc.; and Earlham College from a state college, the state college, that state college, etc. But many phrasal proper names have determinative modifiers as their first word. Literary titles are phrasal proper names that take many forms: in An Enemy of the People the indefinite article is clearly a part of the name. Our Lady of Guadalupe is a phrasal proper name of another kind: the possessive determinative is a part of the name. But the determinative that most often begins phrasal proper names is the definite article the. Except when it begins a literary title (and, of course, when it comes at the first of a sentence), an article beginning a phrasal proper name is usually not begun with a capital letter. In official use, however, sometimes it is. In my own experience, in official documents and publications both The University of Texas and The Youngstown Sheet and Tube Company use an initial capital letter in the article which begins their names, or have done so until recently. I note with interest that in a recent (1966) issue of Language when Professor Sledd comments that "whole school systems plunge from one morass into another in pursuit of The New English," he begins the article in the phrase The New English with a capital letter as a part of the process of making an ironic mock proper name out of the phrase. The official name The Johns Hopkins University employs an article which is not likely to occur at all in unofficial use, and begins it with a capital letter. 
Some phrasal proper names are apposed units in internal form: Edward the Confessor and William the Silent are examples of such names. More often in the world of today, phrasal proper names can be multiple units in internal form. One new West Indian republic has such a name: Trinidad and Tobago. Sears, Roebuck and Company and $E$. M. Scarbrough and Sons are such names. I would guess the Anheuser-Busch, Inc., is such a name also, with the hyphen indicating coordination as it does in such a phrase as JapaneseAmerican relations.

Most phrasal proper names are headed units, however. Within them classifying pluralizer nouns such as company, island, state, and university often function as heads. In the following phrasal proper names the head words are singular in form:

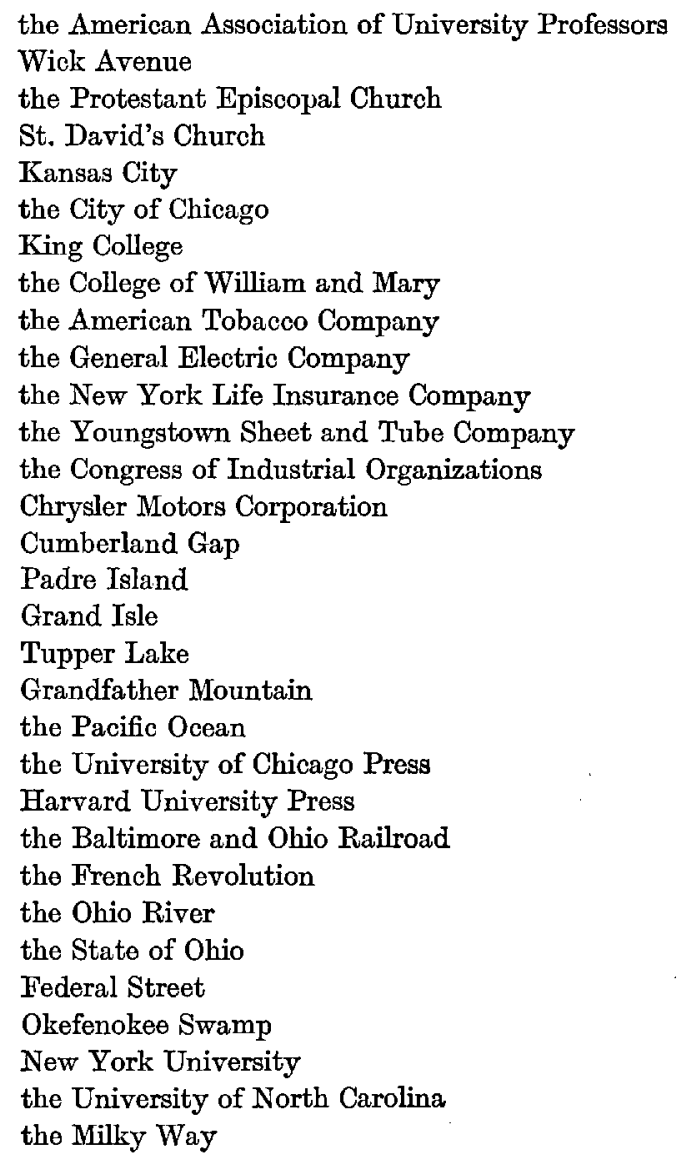


In the following headed-unit proper names the heads are proper nouns:

\author{
New England \\ North Carolina \\ Saint Louis
}

In the following names the heads are plural in form:

\author{
American Airlines \\ Caribbean Atlantic Airlines, Inc. \\ Pan-American World Airways \\ Atlantic Associates \\ Cowles Educational Books, Inc. \\ Coral Gables \\ Moog Industries, Inc. \\ the Windward Islands \\ the British Isles \\ the Great Lakes \\ the Adirondack Mountains \\ Grand Rapids \\ the United States of America
}

Phrasal proper names do not always have the number force their forms suggest. Thus verb forms used with multiple-unit subjects such as Trinidad and Tobago and Sears, Roebuck and Company are commonly singular in form, I believe. Verb forms used with singularform headed-unit subjects such as St. David's Church and the Youngstown Sheet and Tube Company are generally singular in form. Verb forms used with plural-form headed-unit subjects such as American Airlines, Atlantic Associates, and Coral Gables are usually singular; on the other hand, plural verb forms are used when their subjects are plural-form names of chains or comparable groupings of islands, lakes, and mountains. The United States of America is used with singular verb forms; spoken of as a political unit, the United States Virgin Islands is used in the same way, at least part of the time. In informal styles some phrasal proper names exert singular force on verbs of which they are subjects but plural force on pronouns referring to them, so that sentences like the following are not uncommon.

St. David's Church has a new rector they think they will like.

Delta Airlines has a good schedule to New Orleans, and they feed you well too.

In this respect phrasal proper names sometimes behave like the singular forms of collective pluralizers such as family and team. 
The team is in Omaha today, but they'll be back by Monday.

But however much their number force may be confused, phrasal proper nouns do not cross the line between the two numbers clearly and decisively. For this reason Lake Erie is a Great Lake is an unsatisfactory sentence; what is usually said is Lake Erie is one of the Great Lakes, which maintains the plural form of the proper name the Great Lakes.

Shorter forms of many phrasal proper names such as have just been noted exist alongside these forms. Thus alongside official names such as the City of Chicago and the State of Ohio, with the proper nouns Chicago and Ohio incorporated in prepositional modifiers, the proper nouns are much more commonly used alone, as fully adequate proper names in themselves. Alongside such names as the Pacific Ocean, the Windward Islands, and the Adirondack Mountains shorter phrasal names without the pluralizer-noun heads of the longer names (ocean, island, mountain) have very considerable use. When we compare such shorter names as the Windwards with such longer names as the Windward Islands, we notice a curious shift in construetion. In the Windward Islands the word windward is an adjective and is one of two layered modifiers of the head word that terminates the name: in the Windwards the word Windwards is terminal and is a true plural proper noun, carrying inflection for the plural and modified by the article that precedes it. The contrast between the official name the United States of America and the more usual the United States is grammatically less complex: the shorter form merely lacks the prepositional modifier terminating the longer. When the still shorter name the States is employed, the pluralizernoun head has only one modifier, the article the.

We would be on shaky ground if we described proper names such as Ohio as reductions of longer proper names such as the State of Ohio, or proper names such as the Ohio as reductions of longer proper names such as the Ohio River. It is safer to say simply that names of two kinds exist side by side here. And of course we cannot regard Chicago as a reduction of Chicago, Illinois - which is a sequence of a kind the written language refuses to treat as a tight unit. But when we compare commercial and institutional short-form proper names with their longer equivalents, we seem to be justified in speaking of reduction. Such reduction is of different types, some of them of considerable grammatical interest. 
When Sears, Roebuck and Company is reduced to Sears, two of the three coordinates of the multiple-unit full name have been dropped. When E. M. Scarbrough and Sons becomes Scarbrough's, multiple-unit construction has been abandoned again and possessive construction like that found in such short forms as St. David's, which occurs alongside St. David's Church, has been added. When Texas Christian University becomes T.C.U., letters have replaced words. When American Airlines becomes American, we find ourselves with a pair grammatically similar to the Windward Islands and the Windwards. In American Airlines has a night flight to Dallas the adjective American is modifier and the pluralizer noun airlines is head within the phrasal-proper-name subject, which is singular in force in spite of its plural form. In American has a night fight to Dallas the subject American is a proper noun quite distinct from both the adjective American and the pluralizer noun of nationality used in there was another American on the bus to Morelia. When the General Electric Company becomes General Electric, of the three layered modifiers and a head that make up the longer proper name only two modifiers remain. In the short-form phrasal proper name General Electric the adjective General modifies the adjective Electric. When the New England Mutual Life Insurance Company becomes New England Life, the shift in construction is still more complex. In the longer of these two forms, the pluralizer-noun head company is preceded by four layered modifiers - the, New England, mutual, and life insurance. Within the last-named of these modifiers, the noun life is modifier and the noun insurance is head. In New England Life the phrasal proper name New England is modifier and the noun life - all that remains of the innermost modifier of company in the full-form phrasal name - is head. When Fidelity Federal Savings and Loan Association becomes Fidelity Federal Savings, the first coordinate in the innermost of three layered modifiers of the pluralizer-noun head association assumes the construction of head, with a noun and an adjective as layered modifiers. When Caribbean Atlantic Airlines, Inc., becomes Caribair, the second modifying adjective, Atlantic, is dropped and the first modifying adjective, Caribbean, gives way to the shorter noun Carib and is combined with the modifying part of the compound-noun head, airlines, to form a new compound noun that seems to have replaced the official name entirely in advertising and in ordinary correspondence. 
The usefulness of short-form phrasal proper names is obvious. Often several short forms exist side by side, sometimes for use in different situations. As I have suggested, the Youngstown Sheet and Tube Company and the University of Texas have been of some importance in my life. When I worked for the Youngstown Sheet and Tube Company long ago, I usually referred to it as the Sheet and Tube. Mr. Richard Nelson, of the Public Relations Office of the company, tells me that in use in newspapers and on radio and television the name is often shortened to the Sheet and Tube Company, to Youngstown Sheet and Tube, and to Sheet and Tube, the last two shortenings not employing an article. Outside its home area, Mr. Nelson says, the name sometimes becomes simply Youngstown. In advertising, the altered short form Youngstown Steel is now in general use. Around Austin the University of Texas is commonly shortened to the University. At a distance, with sufficient context the proper noun Texas often functions alone as a short form of the University of Texas. In the following sentences Texas is a short form with the value of (1) the State of Texas, (2) Texas Avenue, and (3) the University of Texas.

Jane grew up in Texas.

To get to the airport, we drove east on Texas.

Jones did his undergraduate work at Texas.

The choices of prepositions in these three sentences (first in, then $o n$, then at) reflect the differences in effective meanings retained by the one-word proper noun Texas in these three uses.

Multiword proper names whose internal form is not nounal at all are of considerable interest to the grammarian. The King James Bible, the most important single volume in all the literature of the English language, tells us that when Moses asked to be told God's name God anwered, "I AM THAT I AM," and then added:

Thus shalt thou say unto the children of Israel,

I AM hath sent me unto you.

Given names such as Praise God once had at least a degree of use among those whose language was English: Praise-God Barebone won a place for himself in the history of seventeenth-century England. People's names are increasingly standardized now - and even more standardized numbers are replacing them in more and more 
situations - and no prudent parent would give a child a syntactically unusual phrasal name. But such names survive, and even flourish, on racetracks. Glancing through sports pages in the States, I have noted such names of horses as the following:

$\begin{array}{ll}\text { Strangely Enough } & \text { Inside Out } \\ \text { In Focus } & \text { He's My Boy } \\ \text { Little But Fast } & \text { That's Him Now } \\ \text { Time And Again } & \text { What Now } \\ \text { Gee Judge } & \text { Who's Afraid } \\ \text { Caught Short } & \text { Please Repeat } \\ \text { Blew By } & \text { Pay Now } \\ \text { Back Again } & \text { Hurry Up Dear }\end{array}$

Both the ordinary internal grammatical constructions and the ordinary (non-proper-name) meanings of such sequences as these are reasonably clear, and certainly those who give such names to horses are interested in the ordinary meanings of the sequences. Literary titles constitute another category of proper names whose internal grammatical structure is quite varied, as has been said.

The internal grammatical construction of the various kinds of phrasal proper names discussed thus far is reasonably clear, but the internal construction of some phrasal proper names is not clear. This is the case, first of all, for "full names" of people, such as John Fitzgerald Kennedy, to pick a famous example. John Fitzgerald Kennedy is obviously a sequence made up of three proper nouns, the first two being given names (though the second is commoner as a family name than as a given name) and the third being the family name inherited from the bearer's father. At least two of the three names could function independently of the others as ways of addressing the bearer or referring to him: John Fitzgerald Kennedy could be addressed, or referred to, as John (or Jack) under some circumstances and as Kennedy under others. Some people use their second given names much as first given names are more commonly used, and other people are commonly called by two given names together - John Henry Follett, for example, being known as John Henry. Alphabetical listings - for example, in telephone directories - give attention to family names before given names. Honorific modifiers such as the nouns $M r$., captain, judge, senator, and president normally attach to family names or to name sequences terminating 
in family names; a few honorifies such as Uncle attach to given names or to name sequences beginning with given names, and numeral modifiers such as the third of George III and John Henry Follett III attach to given names and full names. When honorifics interrupt full names, as in Francis Cardinal Spellman, the effect must be described as exotic. Ordinarily honorifies are not parts of proper names but only modifiers of them, but certainly the honorific saint is part of place-names such as St. Louis, St. Paul, and St. Thomas as truly as the Saint of St. Croix is part of that historically distinct name. Moreover, when the wife of a man named George $R$. Holden is called Mrs. George R. Holden the honorific Mrs. plays a major role in identifying her, since without it the name is not hers but her husband's. When junior is used as in Morgan Callaway, Jr., the written language treats it as definitely outside the proper name. Letters often replace given names, as in Harry $S$. Truman, J. Edgar Hoover, and $T$. S. Eliot. In Malcolm $X$ a letter replaces a family name. Full names sometimes function as modifiers and sometimes as heads within larger phrasal proper names: for example, in the A. H. Robins Company and in John H. Breck, Inc. The grammarian must ask what relationship binds such proper nouns as John, Fitzgerald, and Kennedy (and comparably used letters) in full names that obviously form nounal units. His question is concerned with the grammar of the English of today, not with relationships between names in earlier centuries. I am afraid that he cannot answer his question, except to say that such phrasal names are units made up of components that can be described only as items in a string.

There are phrasal proper names of other types in which the relationships uniting components cannot be specified with certainty. Phrasal proper names such as Terre Haute, Puerto Rico, Buenos Aires, Chichén Itzá, and Addis Ababa are learned as units by most of those who use them in English, and usually the relationships uniting the component written-language words are thought of only by people who know something about the languages represented. Probably such names as these should be given part-of-speech classifications only as units: certainly we cannot assign a part-of-speech classification to Itzá or Ababa in English. Topographical names such as Fort Knox, Lake Erie, and Mount Mitchell present a problem of another kind. If we grant that in phrasal proper names such as Tupper Lake and Grandfather Mountain the classifying pluralizer 
nouns, here lake and mountain, are head words modified by what precedes them, then we may want to say that in such names as Fort Knox, Lake Erie, and Mount Mitchell the classifying pluralizer nouns fort, lake, and mount are heads similarly. But one-word nouns used as modifiers do not commonly follow their heads in contemporary English, and we are likely to feel that in Fort Knox, Lake Erie, and Mount Mitchell the head is the terminal proper noun, as in St. Thomas and North Dakota. Still, the saint of St. Thomas is an honorific carried over into the name of the island, and the north of North Dakota is divisional: the fort of Fort Knox, the lake of Lake Erie, and the mount of Mount Mitchell seem like a different kind of thing. I myself am inclined to treat phrasal names of this kind as I do those like John Fitzgerald Kennedy, saying simply that they have components which are obvious but which have uncertain relationships. Naturally it is saddening to have to admit to uncertainty in such matters as these.

So much for what seems to me to be of basic importance to a minimal account of the grammar of phrasal proper names. It seems desirable to comment briefly on two other matters of grammatical interest. Phrasal proper names often take possessive inflection as units. In John Fitzgerald Kennedy's tragic death, for example, the possessive inflectional ending attached to Kennedy clearly belongs to the full name John Fitzgerald Kennedy. But nounal phrases of other kinds take possessive inflection as units too. In my father and mother's friends, for example, the possessive ending attached to mother's clearly relates my father and mother, not just mother, to friends. A second point of some interest is the fact that in the spoken language phrasal proper names often differ in intonation from grammatically parallel nonproper nounal phrases. Thus Long Island commonly differs in intonation from a long island, and Main Streel from the main street. But comparable distinctions are made where proper names are not involved at all. The ordinary pronunciation of a high school, for example, is distinguished in pattern of stresses from the ordinary noncontrastive pronunciation of a new school much as the ordinary pronunciation of Main Street is distinguished from that of the main street. And stresses are variable, especially where contrasts are involved. In dealing with proper names semantic and syntactic criterions are much more manageable than phonological ones. 


\section{III}

So much, then, for what seems to me a minimal content for a section essential to any respectable account of the grammar of contemporary English. It remains to comment briefly on the treatment of proper names in the most influential accounts of English grammar to appear between 1951 and 1966.

Structuralist treatments of English grammar have done very little with proper names. In An Outline of English Structure (1951) Professors Trager and Smith comment on the different patterns of stress employed in the proper name Long Island and the nonproper phrase a long island, but they have nothing to say about proper names as such. Nor, though they insist that morphological analysis must precede syntactic, do they comment on the morphological content of island, which obviously pairs with mainland, or on that of Pennsylvania, which occurs in another phrasal proper name that interests them. In The Structure of English (1952) Professor Fries lists single-word utterances such as Carol, Dad, and Jack and describes them as calls; but in his account of the "formal characteristics" of English nouns he states explicitly that "in this book" he is not concerning himself with proper nouns. In The Structure of American English (1958) Professor Francis mentions "the special groups of nouns and adjectives called proper" and adds that "they can be readily identified without benefit of capitals, as they are in speech," but he does not go beyond this simple comment - even to make clear what he means by grammatically distinct proper adjectives. Elsewhere in the same text he says that "all nouns have four forms, morphemically considered." If taken literally, this rule would eliminate quantifiables such as postage which have no plurals and are not likely to be made possessive; it would also eliminate proper nouns, which are not usable as such in both singular and plural numbers. In An Introduction to Descriptive Linguistics (rev. ed., 1961) Professor Gleason ignores proper names. His characteristic nouns have two forms, a basic singular form and a plural. Professor Gleason considers that in nouns like sheep the plural contains a zero allomorph of plural inflection, and he does recognize a category of quantifiable ("mass") nouns in modern English. The formation of possessives Professor Gleason regards as "better handled" as a matter of syntax, not of inflection. "In English," Professor 
Gleason says, "case is restricted to pronouns," so that the his of his grades is an inflected form of he but the Virginia's of Virginia's grades is not an inflected form of Virginia. Assigning morphology priority over syntax, and assigning the formation of the possessives of nouns to syntax, Professor Gleason's Introduction quite naturally shows no interest in proper nouns. So much for the Structuralist treatments of English grammar whose influence, exerted at advanced levels, has been greatest. Less influential Structuralist texts do give some attention to proper names, but I know of no Structuralist treatments of the topic that I would call impressive.

I know of no satisfying Transformationalist accounts of proper names. In his Syntactic Structures (1957) Professor Chomsky defines the kernel sentence as a union of an NP (or subject) and a VP (or predicate). The NP he defines as a union of a $\mathrm{T}$ (or articledeterminer) and an $\mathrm{N}$ (or noun). In the man hit the ball the subject NP, the man, is divided into the determiner the and the noun man; but Professor Chomsky does not spell out the answer to the question raised in such sentences as George hit the ball and he hit the ball if we look for determiners in their proper-noun and personal-pronoun subjects. In English Syntax (1964) Professor Roberts presents a solution to the problem for the personal pronouns: they contain zero allomorphs of the indefinite article $a$. Actually personal pronouns such as he have the quality of definiteness that that boy has, not the quality of indefiniteness that a boy has; and certainly $I$ and you are definite rather than indefinite in force. In his epochal paper entitled "Co-occurrence and Transformation in Linguistic Structure," in Language (1957), Professor Harris points out that "in The man ... he ..., the pro-morpheme he indicates a recurrence not merely of the morpheme man but of the particular man individuated by its article the." Professor Harris could have gone a step farther. In $a$ man came to see you while you were out, and I told him you would be back by four, the pronoun form him can be replaced by the man or that man but not by a man, which is simply not repeatable applied to the same man. Traditional grammarians have long pointed out the strong resemblances, in grammatical behavior, between personal pronouns such as he and proper nouns such as George. Yet Professor Roberts argues that common nouns are always used with determiners, the determiner often being zero, but proper names are never used with them. The the of the United States, Professor Roberts says, 
is not the definite article. I cannot follow Professor Roberts at all here. He can assign zero determiners to chairman, bacon, and dogs in the following sentences if he wants to.

Maurice was chairman then.

We usually have bacon at breakfast.

Joan likes dogs.

But if precise determiners were used in these three sentences, they would be rather different ones: first the, then some, then most or perhaps some such phrasal determiner as almost all. And there is fully as much reason to assign zero allomorphs of the definite article the to proper nouns when they are used in true proper-noun fashion as to assign zero allomorphs of an article to the personal pronouns. When we say Virginia helps people forget their troubles, we are speaking of a very specific person among the enormous number of people named Virginia. For us at the moment the proper noun Virginia means what is meant by the girl named Virginia that stands out in our thinking at the moment, and this complex equivalent of the simple proper noun certainly requires an initial determinative. It is undeniable that the element of definiteness commonly expressed most economically by the is present when we use proper names such as Virginia in true proper-name fashion. In Aspects of the Theory of Syntax (1965) Professor Chomsky divides nouns into common and proper categories and says that certain rules - "for example, some involving determiners" - distinguish the categories. If he has given an explicit formulation of these rules, I have not seen it.

However, the only post-Aspects "deep structure" Transformational grammar available to me as I put this paper in final form, Professors Jacobs and Rosenbaum's English Transformational Grammar (1968), does say that "noun phrases" can be composed of nouns alone, giving the proper noun Samson as an example, and adds nothing about zero allomorphs of determiners. It is saddening to note that Professors Jacobs and Rosenbaum give very little attention to proper names and even call Sebastian a "count noun," wholly ignoring the fact that when Sebastian is pluralized the central effective meanings that it characteristically carries - whether we use the word of a saint, or of a Portuguese king, or of a restaurant operator in Charlotte Amalie, or of a friend who is known as "Sebastian" to a relatively small circle of relatives, friends, and 
acquaintances - are wholly individual and simply cannot be carried over into pluralizer uses.

In the only Stratificational treatment of English grammar I have seen - Professor Lamb's Outline of Stratificational Grammar (1966) - a category of "personal nouns" including such words as Gordy, Donello, Harriet, and Tubman is recognized in the "lexicon" and again in the "morphicon" included in the specimen of analysis at lexemic and morphemic strata. The honorific $M r$. is called a "personal noun" at the lexemic stratum but a "simple noun" (along with movie, night, and other) at the morphemic stratum. It would seem much better to classify other as a pronoun and such noun honorifics as Mr. (with its plural Messrs.), professor, doctor, and father as pluralizer nouns used as modifiers of true proper nouns and phrasal proper names. There is no discussion of the category of "personal" nouns in Professor Lamb's book. Surely the category needs to be broadened to include place names and the rest, even in an extremely superficial account of modern English grammar.

It is well to face the fact that the very real achievements of American linguistic theoreticians in recent decades have not been in the field of English grammar. General linguistic theory is one thing, the grammatical analysis of a particular language is another. In his excellent An Introduction to General Linguistics (1967) Professor Dinneen warns that "a valid division of labor" seems to exist here. "The reasonably full description of a language" is the work of a lifetime, Professor Dinneen says. I myself would add that a lifetime may very well prove not long enough.

\section{NECROLOGY}

Professor H. J. van de Wijer, Director of the International Centre of Onomastics and editor of Onoma, died at Louvain on December 4,1968 , at the age of 85 . Professor van de Wijer had been responsible for the organizing of the International Centre and for the creation of its journal, Onoma. 